\title{
Health Conditions and Factors Related to the Work Ability of Teachers
}

\author{
Tatiana Giovanelli VEDOVATO $^{1 *}$ and Inês MONTEIRO ${ }^{1}$ \\ ${ }^{1}$ Faculty of Nursing, University of Campinas (UNICAMP), Brazil \\ Received May 9, 2013 and accepted January 6, 2014 \\ Published online in J-STAGE January 15, 2014
}

\begin{abstract}
This is a cross-sectional study conducted with 258 teachers from nine state schools in two municipalities of São Paulo state with the purpose of assessing their work ability. A questionnaire with socio-demographic and health/work conditions data and the Work Ability Index (WAI) was performed. Most teachers were females, $41.9 \mathrm{yr}$ old on average (SD 9.4), and with an undergraduate degree $(95.7 \%)$. The work ability was considered good for $42.6 \%$ and moderate/low for $35.3 \%$. In linear regressions models, which used the two domain model, the significant variables for a decrease in WAI were: individual perception of a worsening in the health situation $(p<0001)$, having children $(p=0.0003 / p=0.0001)$, difficulty in sleeping well at night $(p=0.0009 / p=0.0014)$, history of physical pain in the previous six months $(p<0.0001 / p<0.0001)$, being a teacher with a contract $(p=0.0007)$ and working as a teacher for a longer time. $(p=0.0183)$. Public investments on the work conditions of teachers are important to recover and to maintain their work ability.
\end{abstract}

Key words : Work ability, WAI, Work conditions, Social conditions, Health situation

\section{Introduction}

The work of teachers has a fundamental social value because education can ensure economic growth, and technical and scientific development in any society. In Brazil, there are over 2.6 million teachers working in basic and higher education, and they are responsible for instructing millions of Brazilian students ${ }^{1}$. Teachers are the main responsible for fostering the sense of citizenship in students. They believe that the students will be citizens in the future and will be active in the society with rights and duties ${ }^{2}$.

The physical and mental health of any worker may become one of the determinant factors of the work ability ${ }^{3)}$. It is understood that there is a relationship between work ability and the health of workers associated with several

*To whom correspondence should be addressed.

E-mail: tatigio@fcm.unicamp.br

(C)2014 National Institute of Occupational Safety and Health factors, such as socio-demographic factors, lifestyle, workload and biological aging itself within the work structure $^{3,4)}$. The functional capacity of teachers may be related to psychosocial problems, stress and musculoskeletal damages $^{5}$.

A study ${ }^{6)}$ has found that the presence of many diseases and cardiovascular risk factors could decrease the capacity for work of teachers and office workers. When comparing these professions, teachers had a 1.6 higher risk of work ability impairment compared to office workers. Teachers were more exposed to a heavy workload, which probably affected the retirement due to illness. Brazilian studies have indicated a relationship between the work of the teachers and health problems ${ }^{5,7)}$, emphasizing mental health and psychosocial problems ${ }^{10-12)}$, in addition to voice fatigue ${ }^{13-15)}$.

Studies on work ability were developed by Finnish researchers of the Finnish Institute of Occupational Health Helsinki - Finland, since the beginning of the 1980's and 
their purpose was to prevent the inability to work across aging workers, i.e., in a productive age ${ }^{3,4)}$. The Work Ability Index - WAI - was determined based on the individual answers from the workers to a number of questions that took into account their physical and mental work requirements ${ }^{16)}$. The WAI questionnaire has been translated and is available in 26 languages. Being of great importance for research in these countries, however, its use should not be trivialized as a measure of selection or exclusion of employees, as this practice compromises ethical aspects.

The WAI has a score variation ranging from 7 to 49 points, showing the perception the workers themselves have on their work ability, divided into the following categories: low (7-27 points), moderate (28-36), good (37-43), and excellent work ability (44-49) ${ }^{17)}$. Because this is a widely used questionnaire in occupational health researches covering work requirements, health conditions and mental and physical resources, some researchers ${ }^{18)}$ concerned about the scope of the WAI questionnaire suggested structures with more than one dimension to interpret the "subjectively estimated work ability" and "objective health status"19).

In a German study that aimed to identify the dimensionality of the WAI, the authors analyzed a sample of 321 individuals from different professional groups that included school teachers, office workers, nursery teachers and managers. The authors concluded that the use of the total score of the WAI only did not suit statistical analyzes that evaluated the ability of individuals to work and subsequently developed a two-dimensional structure analysis of the WAI instrument, which can be applied in similar studies ${ }^{19)}$.

A research conducted in Finland with 1,012 teachers ${ }^{20)}$ evaluated the ability to work in the total score of the instrument and concluded that the decrease of the work ability was related to high mental demand experienced in schools, which was generated by time pressure and by dealing with students, triggering stress symptoms and psychosomatic diseases. In a systematic review ${ }^{21)}$ on the effects of individual and work factors related to the work ability, the authors have concluded that the factors associated with this decrease were: lack of pleasure, lack of physical activity, presence of musculoskeletal pain, age, obesity, high demand of mental work, lack of autonomy, inadequate physical workplace and high physical workload .

The relevance of a study with teachers from the Brazilian public system is in the value of the teacher to the society. Preserving the health of teachers is to ensure social sustainability and, moreover, it can contribute to teachers, in general, to realize that some individual factors could ensure them good health even when they are retired. The objective of this study was to explore the relationship between health conditions and the work ability of teachers in state schools in two cities in the state of São Paulo and identify the main factors associated with individual characteristics and health.

\section{Subjects and Methods}

The cross-sectional epidemiological study ${ }^{22)}$ was conducted in two towns in the countryside of the state of São Paulo: São José do Rio Pardo and Campinas, in nine state schools of elementary and/or high school education, intentionally chosen, with an equal participation of teachers in schools from more centralized and also peripheral regions. The mix of sample proportions by quotas according to the different regions of each school chosen in each one of the cities assured characteristics that could reinforce the representativeness of the findings in relation to the reference population, that is, the teachers from public schools of the state of São Paulo.

After contacting the board of directors of each school and obtaining their permission to apply the questionnaires to the teachers, we chose to apply them during the Collective Pedagogic Working Hour (CPWH) weekly meetings due to the difficulty in finding the largest number of teachers during regular class recess times. In addition to $\mathrm{CPWH}$, the researcher remained for a period of time in each school to advertise and request the participation of teachers who did not attend the CPWH meetings. The research was conducted from August to December 2005, and the sample was comprised by 258 teachers, in a population of 468 , with a response rate of $55.1 \%$.

Public elementary and high school teachers were included in the research, from both genders, who accepted to participate in the research signing a consent term. No differences were observed in relation to gender and age among the teacher who participated and who did not participate in the research. Regarding ethical aspects the research was approved by the Research Ethics Board (REB) of the Faculty of Medical Sciences of the University of Campinas - FCM/UNICAMP.

The Work Ability Index (WAI) ${ }^{16)}$ is a self-applicable instrument, and a questionnaire ${ }^{23)}$ was used with sociodemographic data, lifestyle, work, health aspects and occupational risks for data collection. The WAI questionnaire consists of seven subscales related to different aspects of 
Table 1. Work Ability Index (WAI) related to some characteristics of the teachers $(n=258)$

\begin{tabular}{|c|c|c|c|c|c|c|c|c|c|c|c|}
\hline \multirow{3}{*}{ Variable / Category } & \multicolumn{11}{|c|}{ WAI } \\
\hline & Excellent & & Good & & Moderate & & Poor & & Total & & \\
\hline & $\mathrm{n}$ & $\%$ & $\mathrm{n}$ & $\%$ & $\mathrm{n}$ & $\%$ & $\mathrm{n}$ & $\%$ & $\mathrm{n}$ & $\%$ & $p^{*}$ \\
\hline Sex & & & & & & & & & & & 0.1760 \\
\hline Male & 16 & 6.2 & 18 & 6.9 & 10 & 3.9 & 3 & 1.2 & 47 & 18.2 & \\
\hline Female & 41 & 15.9 & 92 & 35.6 & 58 & 22.5 & 20 & 7.8 & 211 & 81.8 & \\
\hline Age (yr) & & & & & & & & & & & 0.0001 \\
\hline$<30$ & 7 & 2.7 & 8 & 3.1 & 5 & 2 & 11 & 4.3 & 31 & 12.1 & \\
\hline $30-40$ & 20 & 7.7 & 35 & 13.6 & 20 & 7.7 & 4 & 1.6 & 79 & 30.6 & \\
\hline $40-50$ & 20 & 7.7 & 41 & 15.9 & 29 & 11.3 & 3 & 1.2 & 93 & 36.1 & \\
\hline$\geq 50$ & 10 & 3.8 & 26 & 10.1 & 14 & 5.4 & 5 & 2 & 55 & 21.3 & \\
\hline Marital Status & & & & & & & & & & & 0.1702 \\
\hline Married & 38 & 14.7 & 71 & 27.5 & 39 & 15.1 & 9 & 3.5 & 157 & 60.8 & \\
\hline Divorced/Widow & 5 & 1.9 & 16 & 6.2 & 10 & 3.9 & 3 & 1.2 & 34 & 13.2 & \\
\hline Single & 14 & 5.4 & 23 & 8.9 & 19 & 7.4 & 11 & 4.3 & 67 & 26 & \\
\hline Number of years as a teacher & & & & & & & & & & & 0.013 \\
\hline$<10$ & 26 & 10.1 & 24 & 9.3 & 21 & 8.1 & 2 & 0.8 & 73 & 28.3 & \\
\hline $10-15$ & 13 & 5 & 33 & 12.8 & 14 & 5.6 & 1 & 0.4 & 61 & 23.6 & \\
\hline $15-20$ & 11 & 4.3 & 30 & 11.6 & 17 & 6.6 & 2 & 0.8 & 60 & 23.3 & \\
\hline$\geq 20$ & 10 & 3.9 & 24 & 9.3 & 23 & 8.9 & 7 & 2.7 & 64 & 24.8 & \\
\hline Compared health & & & & & & & & & & & $<0.0001$ \\
\hline Better/Much better & 41 & 15.9 & 57 & 22.1 & 26 & 10.1 & 2 & 0.8 & 126 & 48.9 & \\
\hline Average & 16 & 6.2 & 47 & 18.2 & 31 & 12 & 11 & 4.3 & 105 & 40.7 & \\
\hline Poor/Little poor & 0 & 0 & 6 & 2.3 & 11 & 4.3 & 10 & 3.9 & 27 & 10.5 & \\
\hline Total & 57 & 22.1 & 110 & 42.6 & 68 & 26.4 & 23 & 8.9 & 258 & 100 & \\
\hline
\end{tabular}

$* p$-value by $\chi^{2}$ test

Table 2. Current work ability (WAI item 1$)$ and teachers self-referred health $(n=258)$

\begin{tabular}{llcccc}
\hline Variable & $\mathrm{n}$ & Mean & SD & $p$-value* \\
\hline Current work ability & $* *$ poor/little poor & 27 & 7.15 & 1.49 & 0.0004 \\
& $* *$ average & 105 & 7.78 & 1.45 & \\
& $* *$ better/much better & 126 & 8.25 & 1.26 & \\
\hline
\end{tabular}

*p-value: Kruskal-Wallis test, ${ }^{*}$ The category - poor/little poor, average and better/much better are from the Occupational Stress Questionnaire - OSQ ${ }^{24)}$

work ability: WAI item 1 refers to current work ability compared to the best period of life of the worker; WAI item 2 is about the work ability concerning to physical and mental demands at work; WAI item 3 - diseases with physician diagnosis; WAI item 4 refers to "estimated work impairment due to diseases"; WAI item 5 - "sick leave during the past year (12 months)"; WAI item 6 - "own prognosis of work ability two years from now" and WAI item 7 - "mental resources"19).

The questionnaire with socio-demographic data QSETES $^{23)}$ has 32 structured questions and five semistructured. Closed questions are answered with just one word or number and/or options of yes or no: origin, sex, age, marital status, children, educational level, work (function, bond, shift, overtime, accident, breaks, individual protection etc.), sleep, house chores, housing, self-referred anthropometric measurements, health compared to other people of the same age, physical pain in the past six months and in the last week, lifestyle (smoking, alcohol intake, physical activity, leisure and medicines), health problems in the last 15 days and risks/hazards at work (position, sound, voice, stress, computer, movements etc.).

The semi-open questions are those that describe what the worker does in his/her work, main previous jobs, the level of tiredness at work, what they like in their work and what their plans for the future are ${ }^{23)}$. One question about 
Table 3. Linear regression with Factor 1 as dependent variable $(n=258)$

\begin{tabular}{|c|c|c|c|c|c|c|}
\hline \multirow{2}{*}{ Factor 1} & \multirow{2}{*}{ Coefficient } & \multirow{2}{*}{ SE } & \multicolumn{2}{|c|}{ Confidence Interval } & \multirow{2}{*}{$p$-value } & \multirow{2}{*}{$\mathrm{R}^{2}$} \\
\hline & & & Lower limit & Upper limit & & \\
\hline Intercept & 32.0993 & 1.3329 & 29.4740 & 34.7246 & $<0.0001$ & 30.91 \\
\hline Professional category & & & & & 0.0021 & \\
\hline Efective* & -3.5445 & 1.0304 & -5.5740 & -1.5150 & 0.0007 & \\
\hline ACT/OFA** & -2.6603 & 1.0006 & -4.6311 & -0.6895 & 0.0084 & \\
\hline \multicolumn{7}{|l|}{ Eventual $^{* * *}$ (ref) } \\
\hline Children & & & & & 0.0003 & \\
\hline No & -1.9131 & 0.5183 & -2.9339 & -0.8922 & 0.0003 & \\
\hline \multicolumn{7}{|l|}{ Yes (ref) } \\
\hline Health compared & & & & & $<0.0001$ & \\
\hline \multicolumn{7}{|l|}{$\dagger$ Poor/little poor (ref) } \\
\hline$\dagger$ Average & 2.5705 & 0.7788 & 1.0366 & 4.1044 & $<0.0001$ & \\
\hline$\dagger$ Better/much better & 3.6401 & 0.7953 & 2.0738 & 5.2064 & 0.0011 & \\
\hline Pain - last six months & & & & & $<0.0001$ & \\
\hline No & 2.0361 & 0.4965 & 1.0582 & 3.0140 & $<0.0001$ & \\
\hline \multicolumn{7}{|l|}{ Yes (ref) } \\
\hline Can not sleep & & & & & 0.0009 & \\
\hline \multicolumn{7}{|l|}{ No (ref) } \\
\hline Yes & 1.9058 & 0.5686 & 0.7859 & 3.0258 & 0.0009 & \\
\hline
\end{tabular}

*Effective teachers were gazzeted by the State. They have job stability. **ACT/OFA teachers were hired temporary job by the State. They do not have approval in public contest. ***Eventual teachers were at the beginning of their career and without approval in public contest. $\dagger$ The category - poor/little poor, average and better/much better are from the Occupational Stress Questionnaire - OSQ ${ }^{24)}$

health compared to people of the same age from the Occupational Stress Questionnaire ${ }^{24)}$ was answered and the responses were better/much better, average and poor/little poor.

In this research with Brazilian teachers performed statistical analyzes with the WAI score ranging between seven and 49 points and was also used the "two factor model / two- dimensional structure"19) with two domains for the WAI: Factor 1 "estimated subjectively work ability" - including WAI items 1, 2, 4, 6 and 7, ranging from 5-37 points and the second domain - Factor 2, "objective health status" including items 3, 4, 5 and 6, ranging from 4-25 points.

Therefore, in order to investigate possible predictive factors for the two domains of the WAI multiple linear regression models were constructed ${ }^{25)}$, in which the scores of the two domains were considered as dependent variables and the other variables as independent. Moreover, they are adjusted for age and gender. For all analyzes, the stepwise variable selection method was used. The results were presented by regression coefficients, standard errors, confidence intervals, and $p$-value. It was also reported the value of the coefficient of determination $\mathrm{R}^{2}$ for each of the fitted models.
A plausible justification for using two-factor model is related to the fact that the seven areas of WAI are measuring tools for two different underlying constructs, meaning that the total score alone could not adequately describe the ability to work and so it was divided into two domains ${ }^{19}$. For all the statistical analyzes, the significance level adopted for the tests was 5\%, that is, $p<0: 05$ and the statistical software used was System for Windows (Statistical Analysis System, version 9.2) SAS $^{\circledR}$.

\section{Results}

Most teachers were females (81.8\%), married (60.8\%) and had children (85.9\%). The average age was $41.4 \mathrm{yr}$ old (SD 9.4) and ranged from 20 to $65 \mathrm{yr}$ old, and $74.4 \%$ were up to $49 \mathrm{yr}$ old. The teachers had a higher education degree $(95.7 \%)$, and among them, $15.1 \%$ were graduate (Master's, PhD's or Specialization Degree). Below, the categorical distribution of the Work Ability Index (WAI) is presented, according to the described variables on gender, age, marital status, time working as a teacher, and individual health perception when compared to other people of the same age (Table 1).

The age, number of years as a teacher and individual 
Table 4. Linear regression with Factor 2 as dependent variable $(n=258)$

\begin{tabular}{|c|c|c|c|c|c|c|}
\hline \multirow{2}{*}{ Factor 2} & \multirow{2}{*}{ Coefficient } & \multirow{2}{*}{ SE } & \multicolumn{2}{|c|}{ Confidence Interval } & \multirow{2}{*}{$p$-value } & \multirow{2}{*}{$\mathrm{R}^{2}$} \\
\hline & & & Lower limit & Upper limit & & \\
\hline Intercept & 20.3569 & 1.3001 & 17.7963 & 22.9174 & $<0.0001$ & 36.82 \\
\hline Children & & & & & 0.0001 & \\
\hline No & -1.8752 & 0.4805 & -2.8215 & -0.9289 & 0.0001 & \\
\hline \multicolumn{7}{|l|}{ Yes (ref) } \\
\hline Number of years as a teacher & -0.0900 & 0.0381 & -0.1649 & -0.0150 & 0.0189 & \\
\hline Pain - last six months & & & & & $<0.0001$ & \\
\hline No & 3.8300 & 0.4438 & 2.9560 & 4.7039 & $<0.0001$ & \\
\hline \multicolumn{7}{|l|}{ Yes (ref) } \\
\hline Can not sleep & & & & & 0.0014 & \\
\hline \multicolumn{7}{|l|}{ No (ref) } \\
\hline Yes & 1.7140 & 0.5310 & 0.6681 & 2.7598 & 0.0014 & \\
\hline
\end{tabular}

health perception variables stand out, which were significantly associated with a reduced work ability of the teacher. The gender variable was significant in the MannWhitney test when WAI was compared $(p=0.0481)$, and women presented a lower value than men. The WAI average of the studied teachers was 38.6 points (SD 5.8), 38.2 points (SD 5.8) among women, and 40.3 (SD 5.6) among men. Women from 40 to $50 \mathrm{yr}$ old presented a $38.1 \mathrm{WAI}$ (SD 5.6), and, among men, it represented 41.6 (SD 4.6).

Regarding the individual health perception of teachers when compared to other people of the same age, it was evidenced that $40.7 \%$ considered that their health was equal to the health of other persons with the same age; $48.8 \%$ said it was better/much better, and $10.5 \%$ poor/little poor.

Comparing the WAI total score and the individual health perception of teachers, the result was significant for those who considered they had a worse and slightly worse health situation, with WAI in the moderate range (28 to 36 points); and $37.1 \%$ who felt they had a worse and slightly worse health situation had a low WAI (7 to 27 points), both with $p$-value lower than 0.0001 ( $\chi^{2}$ test).

Another comparative test was conducted to confirm this result using the individual health perception of teachers only WAI item 1 - "current work ability compared with the lifetime best" (Table 2).

In this model the stepwise process for selection of the variables was used and adjusted for age and sex. The analyses considered in Factor 1 with WAI items 1, 2, 4 and 6 are presented (Table 3 ).

Below are the analyses considered in Factor 2, WAI items 3, 4 and 5 (Table 4).

As to the lifestyle, it was observed that most of them were involved in leisure activities (93.4\%), and only $56.6 \%$ practiced at least one physical activity regularly. Regarding smoking habits and drinking alcohol, 27.5\% answered affirmatively and $9.3 \%$ were smokers, smoking on average, 13.3 (SD 8.4) cigarettes a day.

The main diseases that were self-reported by teachers (71.3\%) were: lumbar region disorder $(37.6 \%)$, followed by accidental injury on the hand, arm, leg and foot (21.7\%) and mild emotional disorder (19\%); and those with medical diagnosis (82.2\%) were: "musculoskeletal disease: upper and lower back and sciatica" (28.7\%); "injury from accident" (19.8\%) and "slight mental disorder/problem" (17.8\%) (Fig. 1).

\section{Discussion}

The prevalence of females teaching in elementary and high school education is similar to what was reported by other authors in researches carried out with teachers $^{7-12)}$. The WAI average for women was two points lower in comparison to men. This fact may be related to several factors, among which are the double working shift between school and household chores, as $92.9 \%$ of the interviewed women also had domestic chores $\left(\chi^{2}\right.$ test, $p$ $<0001)$. In addition to household chores, $66.3 \%$ of teachers had children and child care presents itself as a task performed by teachers, especially women.

The double shift for women is a complex issue. It can be responsible for several factors that decrease women's health, such as greater psychological and physical work overload, insufficient time for leisure, rest and sleep hours $^{7)}$. Other studies ${ }^{26,27)}$ have also associated the demands of work and household chores to poor physical and 


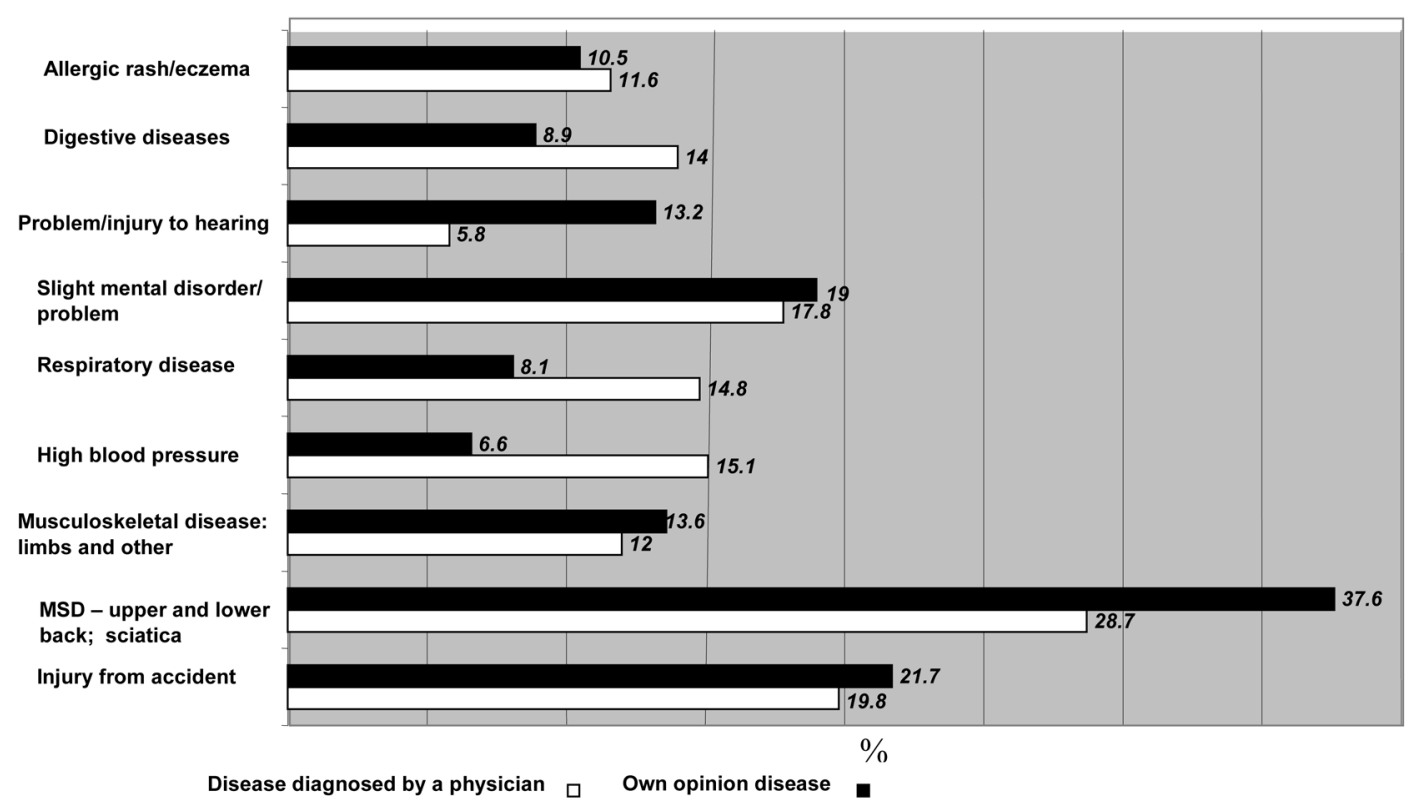

Fig. 1. Prevalence of the diseases according to the opinion of the teachers and the medically diagnosed diseases.

mental health because the subjects of this research entailed little life satisfaction, high levels of stress, less time for physical activity and greater likelihood of drinking alcohol.

Oftentimes, when the work overload is beyond the capacity of the worker, it may be reflected as fatigue manifestations, work absences, incidence of musculoskeletal disorders and mental disorders ${ }^{28)}$, considering that these two last findings are similar to this study (Fig. 1).

Another important aspect was the decrease of WAI values for older age groups and those with higher experience time working as teachers. European studies have shown that most workers while occupying any job have their work ability reduced according to the functional aging of the organism ${ }^{3,4)}$.

This was confirmed in this study because teachers who had a contract were the ones with longer careers because they were hired with a permanent contract and would only leave the profession through retirement. This was highlighted in the analysis model as dependent on Factor 1 - "subjectively estimated work ability" (Table 3 ) and in the Factor model 2 - "objective health status" (Table 4), however, in this analysis it was not the professional category that was associated with lower scores of ability, but the length of employment, which implied that the longer in the profession, the older this teacher was.

In this study the presence of physical pain stood out among teachers, since the variable physical pain in the past six months both in linear regression analysis with dependent variable Factor 1, as in the analysis with the dependent variable Factor 2 showed reduced work ability. Physical pain can be a constant in the life of the education professional, especially musculoskeletal pain ${ }^{8)}$, mainly due to excessive workload by physical exertion performed daily in schools. Besides teachers, other workers ${ }^{29)}$ also have musculoskeletal symptoms associated to reduced work ability.

As to the self-referred health, significant results for those who considered their health worse and a little worse, the WAI tended to lower scores when analyzing the total score and also when we used only the subscale of the WAI item 1 - current work ability - the $p$-value was significant. Using this type of analysis has been common in work ability researches ${ }^{30}$, because the validity and similarity in results between WAI score and one question value, as the question 1 , confirm the veracity of the analysis.

There were differences between the diseases with physician diagnosis $(28.7 \%)$ and the diseases the teachers had in their own opinion (37.6\%). This discrepancy may be a negative factor for the absence of teachers in the studied public schools, since $38.4 \%$ of the teachers were absent from work from one to nine days due to some health problem, medical appointment or to undergo clinical examinations in previous twelve months. It was observed that these absences could be related to the total workload in schools, because $97.7 \%$ of the teachers had an average of $35.1 \mathrm{~h}$ (SD 12.2) during the week, in addition to the hours spent working at home, for extra-class work for most of these 
teachers.

There are limitations in this study. Since this was a cross-sectional research, cause and effect relationships cannot be established; the analyzed data occurred only during a period of time; the results may be representative only for the teachers who worked in the nine state schools that participated in this research, whereas both the teachers who were absent from work, due to diseases, and those who had different roles at the schools did not participate in this research.

In conclusion, in this study, the teachers were mostly women, married, with children and working as teachers for over $15 \mathrm{yr}$. Most of them had a good or excellent WAI; however, a portion of young women, under $30 \mathrm{yr}$ old, were in the moderate or poor category.

Some health conditions were associated with reduced work ability among teachers, and stood out: being a teacher with permanent contract with more time (in years) of profession; having children, the presence of physical pain in the past six months, self-referred health compared with people of the same age as being poor/little poor and not sleeping well at night. Such health conditions and also individual factors could have a direct association with the high percentage of diseases diagnosed by a physician and "own opinion diseases" related by teachers.

Public investment is crucial to encourage health programs for public school in order to promote more health to teachers, as they are professionals with high social value in the upbringing of future citizens of any nation.

\section{Acknowledgement}

Grant from "Coordenação de Aperfeiçoamento de Pessoal de Nível Superior" - CAPES - master's scholarship.

\section{References}

1) Instituto Nacional de Estudos e Pesquisas Educacionais Anísio Teixeira (INEP) (BR). Estudo mostra a situação do professor brasileiro 2003. http://portal.inep.gov.br/c/ journal/view_article_content?groupId $=10157 \&$ articleId $=14$ 054\&version=1.0. Accessed March 23, 2012.

2) Bydlowski CR, Lefèvre AM, Pereira IMTB (2011) [Health promotion and citizenship: the perception of the teacher about citizenship]. Cien Saude Colet 16, 1771-80. [Medline] [CrossRef]

3) Ilmarinen JE (2001) Aging workers. Occup Environ Med 58, 546-52. [Medline] [CrossRef]

4) Tuomi K, Ilmarinen J, Klockars M, Nygård CH, Seitsamo J, Huuhtanen P, Martikainen R, Aalto L (1997) Finnish research project on aging workers in 1981-1992. Scand J
Work Environ Health 23 Suppl 1, 7-11. [Medline]

5) Freude G, Seibt R, Pech EUllsperger (2005) Assessment of work ability and vitality - a study of teachers of different age groups. Anais International Congress Series 1280, 270-74.

6) Seibt R, Spitzer S, Blank M, Scheuch K (2009) Predictors of work ability in occupations with psychological stress. J Public Health 17, 9-18. [CrossRef]

7) Araújo TM, Godinho TM, Reis EJFB, Almeida MMG (2006) Gender differentials and health impacts in the teaching profession. Cien Saude Colet 11, 1117-29.

8) Ribeiro IQB, Araújo TM, Carvalho FM, Porto LA, Reis EFJB (2011) Occupational factors associated to musculoskeletal pain among teachers. Rev Baiana Saud Publ 35, 42-64.

9) Vedovato TG, Monteiro MI (2008) [Socio-demographic profile and health and working conditions of teachers of nine state of São Paulo public schools]. Rev Esc Enferm USP 42, 290-7. [Medline]

10) Carlotto MS, Palazzo LS (2006) [Factors associated with burnout's syndrome: an epidemiological study of teachers]. Cad Saude Publica 22, 1017-26. [Medline]

11) Gasparini SM, Barreto SM, Assunção AA (2006) [Prevalence of common mental disorders among schoolteachers in Belo Horizonte, Minas Gerais, Brazil]. Cad Saude Publica 22, 2679-91. [Medline] [CrossRef]

12) Rocha VM, Fernandes MH (2008) Quality of life elementary school teachers: a perspective for health promotion of worker. J Bras Psiquiatr 57, 23-7.

13) Alves LA, do Carmo Cruz Robazzi ML, Marziale MHP, de Felippe AC, da Conceição Romano C (2009) Health disorders and teachers' voices: a workers' health issue. Rev Lat Am Enfermagem 17, 566-72. [Medline] [CrossRef]

14) Souza CL, Carvalho FM, Araújo TM, Reis EJFB, Lima VMC, Porto LA (2011) Factors associated with vocal fold pathologies in teachers. Rev Saude Publica 45, 914-21. [Medline] [CrossRef]

15) Behlau M, Zambon F, Guerrieri AC, Roy N (2012) Epidemiology of voice disorders in teachers and nonteachers in Brazil: prevalence and adverse effects. J Voice 26, e9-18. [Medline] [CrossRef]

16) Tuomi K, Ilmarinen J, Jahkola A, Katajarine L, Tulkki A (1998) Work Ability Index, Finnish Institute of Occupational Health, Helsinki.

17) Ilmarinen J (2009) Work ability—a comprehensive concept for occupational health research and prevention. Scand J Work Environ Health 35, 1-5. [Medline] [CrossRef]

18) Radkiewicz P, Widerszal-Bazyla M (2005) Psychometric properties of Work Ability Index in the light of comparative survey study. Anais International Congress Series 1280, 304-09.

19) Martus P, Jakob O, Rose U, Seibt R, Freude G (2010) A comparative analysis of the Work Ability Index. Occup Med (Lond) 60, 517-24. [Medline] [CrossRef]

20) Parkatti T, Kinnunen U, Rasku A (1999) Work, well-being 
and health among ageing teachers. In: Finn Age - Respect for the ageing, Ilmarinen J, Louhevaara V (Eds.), 163-71, FIOH, Helsinki.

21) van den Berg TIJ, Elders LAM, de Zwart BCH, Burdorf A (2009) The effects of work-related and individual factors on the Work Ability Index: a systematic review. Occup Environ Med 66, 211-20. [Medline] [CrossRef]

22) Checkoway H, Pearce N, Crawford-Brown DJ (1989) Research methods in occupational epidemiology. Oxford University Press, New York.

23) Monteiro MI (1996, 2005) Questionário para coleta de dados sociodemográficos, aspectos de saúde, trabalho e estilo de vida - QSETS. [Socio-demographic, work, health and life style questionnaire. Work and Health Research Group]. University of Campinas, Campinas - Brazil.

24) Elo AE, Leppänen A, Lindström K (1992) Occupational Stress Questionnaire: user's instructions. FIOH, Helsinki.

25) Montgomery DC, Peck EA (1982) Introduction to linear regression analysis. John Wiley, New York.

26) Allen TD, Herst DE, Bruck CS, Sutton M (2000)
Consequences associated with work-to-family conflict: a review and agenda for future research. J Occup Health Psychol 5, 278-308. [Medline] [CrossRef]

27) Rose S, Hunt T, Ayres BAdjust the balance: literature review life cycles and work life balance 2007. http://www. equalworks.co.uk/resources/contentfiles/4912.pdf. Accessed September 30, 2013.

28) Frutuoso JT, Cruz RM (2005) Work load evaluation and its relation with workers' health conditions. Rev Bras Med Trab 3, 29-36.

29) Sormunen E, Remes J, Hassi J, Pienimäki T, Rintamäki H (2009) Factors associated with self-estimated work ability and musculoskeletal symptoms among male and female workers in cooled food-processing facilities. Ind Health 47, 271-82. [Medline] [CrossRef]

30) El Fassi M, Bocquet V, Majery N, Lair ML, Couffignal S, Mairiaux P (2013) Work ability assessment in a worker population: comparison and determinants of work ability index and work ability score. BMC Public Health 13, 305. [Medline] [CrossRef] 